Armstrong and Ferrari-Bridgers. Critical listening skills in EMT students.

https://doi.org/10.32378/ijp.v4i2.192

\title{
Improving Critical Listening skills in EMT Students
}

Armstrong, Daniel and Ferrari-Bridgers, Franca

Accepted for publication in Irish Journal of Paramedicine, Vol 4, Issue 2. This is the accepted

version of the article, post peer-review. A final publisher version will be provided in due course.

Introduction: Although the importance of EMT students utilizing critical listening skills is apparent, there is little research focused on EMT students or EMTs and critical listening. Ensuring EMT students develop critical listening skills can be an asset that reaches beyond the goal of improving their education. It also has the potential to improve the quality of care they go on to deliver. EMTs may have the only verbal contact with the patient while they are still conscious, or with bystanders that witnessed the incident, or family members/health aides that can give vitally important information on the patient's condition. If an EMT is not adept at critical listening, vital information may be lost, and the repercussions can be serious. This project was designed to determine whether EMT student critical listening ability and class performance would improve from engaging in critical listening exercises.

Methods: Critical listening exercises were emphasized during an EMT course by assessing student knowledge of the Patient Assessment module through two listening exercises modelled after the Ferrari, Lynch, and Vogel Listening Test that measures for critical listening skills. The Patient Assessment module was assessed twice within four weeks in a test-retest design.

Results: The data analysis of a total of $n=51$ students' performance in the pre and postassessments yielded positive results and showed students significantly improved their listening 
Armstrong and Ferrari-Bridgers. Critical listening skills in EMT students.

https://doi.org/10.32378/ijp.v4i2.192

ability within the four-week period. An overall score increase of $34.50 \%$ was found between the pre and the post assessment results. Moreover, the data analysis showed that as the result of the listening exercises, students scored significantly higher in the section of the certifying exam that included critical listening exercises than in all other sections.

Conclusion: The results suggest performing critical listening exercises and assessments can help EMT students properly develop critical listening skills and improve performance.

Keywords: EMT; education; critical listening; EMS 


\section{Introduction}

Emergency medical technicians (EMT) are often the only healthcare providers that travel to the scene of an emergency and they may have the only verbal contact with the patient while they are still conscious, or with bystanders that witnessed the incident, or family members that can give vitally important information on the patient's condition. Ensuring that EMTs develop critical listening skills while in training can be an asset that reaches beyond the goal of improving EMT students' individual education; it has also the potential to improve the quality of care. Although the importance of EMT students and EMTs utilizing critical listening skills is apparent, there is little research on critical listening in emergency medical service (EMS) and in the healthcare field in general. This lack of research may be because the interaction between healthcare providers and patients is more focused on establishing a medical diagnosis rather than on listening to the patient (1-2).

In the healthcare literature several studies have focused on the importance of healthcare providers developing active listening skills such as asking open ended questions, summarizing, and rephrasing patient's narratives for clarification (3-4). These studies pay particular attention to both verbal and nonverbal clues that healthcare providers use to express themselves like acknowledging a patient's suffering and allowing an opportunity for them to speak (2). Another study looks at how physicians, nurses and hospital administrators internalize four conceptualizations of listening constructs (i) listening as organizing information; (ii) listening for relationship building; (iii) critical listening, and (iv) listening for learning and integrating information. The results of the study suggest, physicians, nurses and hospital administrators 
Armstrong and Ferrari-Bridgers. Critical listening skills in EMT students.

https://doi.org/10.32378/ijp.v4i2.192

scored differently on constructs (i), (ii) and (iv); but not on (iii) critical listening that they believe is correlated to actions such as arguing, inquiring, testing, conceding, being critical, answering, and obeying (5-6). The lack of significance for all the three providers with regards to the construct of critical listening is indicative of "a hierarchical and paternalistic relationship between the physician and patient" promoted by the role providers play in a healthcare setting that prefers the avoidance of critical dialogue between healthcare providers and patients (5-8).

This historical paternalistic relationship and lack of critical dialogue deemphasize the importance of listening ability in healthcare providers. Healthcare providers with deficient or defective active listening skills can result in them obtaining an incomplete medical history, misdiagnosing a patient, or creating a loss of trust between the patient and provider. (5). A perceived lack of good listening skills and empathy can also make patients feel their physicians are falling short during many interactions (9). Problems include failing to ask questions, an inability to listen empathically, or failing to notice a patients' emotional reaction. When combined with the pressure physicians face to cut time spent with patients for financial reasons, these factors can lead to serious consequences (10). Moreover, many studies also show how time, empathy, trust, malpractice lawsuits and patient satisfaction are all correlated to listening skills (11-16).

From the patient perspective, patients value good listening skills in their doctors for three reasons: (i) good listening helps clinicians to gather good clinical data from the patients and consequently helps to perform a better diagnosis; (ii) listening is viewed as a means of creating stronger doctor-patient relationships and; (iii) being listened to is perceived by patients as an agent of the healing process (17). In fact, according to another study on listening for feeling in 
Armstrong and Ferrari-Bridgers. Critical listening skills in EMT students.

https://doi.org/10.32378/ijp.v4i2.192

the medical field, there is abundant evidence that patients' emotions are an integral part of the process of care - "there is evidence that when a physician acknowledges and responds to emotion in a consultation, there is improved patient satisfaction, greater likelihood of adherence to medical recommendations, and measurable outcomes such as improved blood pressure and blood sugar" (18). However, it is equally important to point that many healthcare providers receive no or minimal training in listening skills. According to one study most of the physicians interviewed admitted not having received any formal listening training, despite all perceiving listening skills as "extremely important to the medical encounter with patients" (19)

With regards to critical listening skills in Emergency Medicine, studies examining patienthealthcare provider interactions from the patient's perspective have showed that listening practices have become fundamental when aiming to build a more effective patient-provider relationship $(2,16)$. Active, critical and empathic listening skills have been recognized as vital in helping practitioners read patients' verbal and nonverbal clues for a better understanding of how patients experience illnesses (20). This is especially true when it comes to making quick decisions in life threatening situations like in emergency medical care. In one study it was found that the fragmented nature of the patient- provider communication and the provider's failure to build a rapport with the patient are two major aspects of communication error in the emergency room that can negatively affect quality of care (21). In one study it was found that the fragmented nature of the patient- provider communication and the provider's failure to build a rapport with the patient are the two major sources of communication error in the emergency room (20). The combination of several interruptions, multi-tasking and engaging in multiple conversations at once are all possible sources of clinical error (22). Therefore, teaching critical 
Armstrong and Ferrari-Bridgers. Critical listening skills in EMT students.

https://doi.org/10.32378/ijp.v4i2.192

listening skills to healthcare providers is an ethical and pragmatic imperative needed to improve the quality of the health care system. The impact of these factors on EMTs is exemplified in a paramedic's interview statement on the effectiveness of communicating with emergency room staff: 'Nurses are multitasked so they are trying to do 4 or 5 things at once so they are not being overtly attentive, or not listening at all, or are continuously interrupting your train of thought by getting you to move the patient across or do this or do that and then getting you to restart the handover again" (23)

When EMT students enter the field, they will be faced with the same challenges these other healthcare providers face plus many more including; limited contact time, patients with challenging behaviors, patients with problematic conditions, multi-tasking, and communicating with other first responders. These challenges are common and can easily become sources of error which compromise patient care and safety (21). If the EMT does not learn to be adept at listening, this information may be lost with detrimental repercussions on patient care.

\section{The Present Study}

The lack of studies in EMS and the importance of critical listening skills in healthcare led us to design this study that aimed to assess and measure EMT students' critical listening skills. We designed our study adopting Ferrari-Bridgers, Lynch \& Vogel's (24) definition of critical listening. The literature reveals different definitions related to critical listening skills. Critical listening has been linked to comprehension, interpretation and evaluation of a message (20, 2630). More recently, critical listening skills have been associated with the act of arguing, inquiring, testing, being critical, and answering towards a specific message (31). However, in 
Armstrong and Ferrari-Bridgers. Critical listening skills in EMT students.

https://doi.org/10.32378/ijp.v4i2.192

this study we adopted the definition of critical listening skills that is specifically adapted to a classroom setting (25). Critical listening skills are defined by Ferrari-Bridgers et. al. (24) as "the listener's analytical ability to evaluate on the basis of prior knowledge whether (a) the content of the message does or does not comply with specific patterns and/or structural requirements that constitute the structure of the message itself, and (b) whether the content of the message is complete and accurate". According to Ferrari-Bridgers et al. (24) developing critical listening skills teaches students how to quickly recognize whether the content of a message is correct, complete, faulty, illogical, missing and/or incomplete. Consequently, discerning the exactitude of a message helps the listener to give the appropriate feedback to the message that in the case of an emergency could be vital to solve the issue at hand.

To assess listening in this study we utilized the Ferrari Lynch Vogel Listening Test (FLVLT) to assess EMT students' critical listening skills in a classroom setting. The FLVLT has been used to measure critical listening skills in math, computer science, business and speech students (24). The results from these two previous studies showed the FLVLT is an effective instrument to measure critical listening skills across disciplines and how assessing course content through a listening exercise can have positive impact on student learning.

It is important to note that the FLVLT was not designed to measure students' knowledge and familiarity with a topic. The FLVLT was designed to measure critical listening skills; i.e., the students' ability to listen critically to a text, detecting missing parts, errors, inverted sequences and all other biases that the test may contain. These skills are not necessarily related to how 
Armstrong and Ferrari-Bridgers. Critical listening skills in EMT students.

https://doi.org/10.32378/ijp.v4i2.192

familiar or knowledgeable a listener is with a specific topic, but they are related to the students' ability to assess the validity of a message in terms of its internal consistency and errors.

Obviously, while listening, knowledge about a topic can facilitate understanding, but current research in critical listening does not show a clear indication on the effects of prior knowledge and familiarity on students' critical listening skills. However, findings in listening comprehension and second language studies (32-35) seem to indirectly suggest that good listeners are not necessarily those who know more about a topic. In the experiments conducted in the aforementioned studies, prior knowledge of a topic was not found to be a predictor of the level of understanding in a conversation showing that there was no clear interaction between prior knowledge and listening skills for comprehension. In fact, listening comprehension depends more on how proficient students are as listeners rather than how knowledgeable they are on a topic (35).

The present study has two main objectives (A) measuring if EMT students can improve listening skills by incorporating listening exercises into their coursework and (B) ascertaining whether assessing listening skills has positive effects on students' learning and performance on the specific module in which listening exercises were utilized.

Following Ferrari-Bridgers et. al.'s (24-26) results, we assumed that EMT students in this study would also show improvement in their critical listening skills and it would be positively reflected on exam performance.

\section{Methods}

In this study the investigators measured critical listening skills in EMT students during the course of their one semester training program. The study was reviewed and approved by the 
Armstrong and Ferrari-Bridgers. Critical listening skills in EMT students.

https://doi.org/10.32378/ijp.v4i2.192

Queensborough Community College institutional review board. Participants in the study were recruited to participate by their instructor via a consent script read to them orally in the classroom to take part in critical listening exercises. A hard copy of the consent script was also given to the students. Student participation was voluntary, and they were instructed they could withdraw or stop at any point during any of the activities associated with the assessment. Over the three courses examined only four students chose not to participate.

The research design utilized was a test-retest design. Students were assessed twice in the course of the semester. The listening procedure and assessment selected for use in this study was the Ferrari, Lynch, and Vogel Listening Test (FLVLT) (24). The FLVLT is built following specific guidelines for content, assessment design and administration. As far as content, the FLVLT is designed to measure students' performance on a course topic which students have learned, preferably a topic, a module, or a construct that is structured as a stepwise processes, e.g., how to solve an equation, how an organism develops, how to set up a network so on so forth.

Moreover, in order to assess whether students exercise their ability to infer the logic, accuracy, and completeness of the message, the content of FLVLT is presented to the listeners in a defective manner, i.e., with some important steps missing, inaccurate steps, and incomplete information. The content of the FLVLT is presented through a video or a voice enhanced power point presentation whose length varies between 1 to 5 minutes. While watching students are asked to answer a series of closed factual questions, i.e., yes/no questions, recall questions (how many, how often?) built with the purpose of helping students to ascertain whether the message in question reflected the accuracy and completeness of the content learned. In order to measure changes in students' development of critical listening skills and student learning of a new 
Armstrong and Ferrari-Bridgers. Critical listening skills in EMT students.

https://doi.org/10.32378/ijp.v4i2.192

module/construct the FLVLT is administered twice. The pre-assessment is administered right after students have been briefly introduced to the content of the topic or module. The postassessment is administered after students have been taught, practiced, and tested on the topic or module in question. The time between the pre and post assessment varies from a minimum of two weeks to a maximum of seven weeks.

The FLVLT procedure for emergency medicine was designed following the guidelines given above (23). The content of emergency medical technician FLVLT assessment followed a construct/module that students have been taught. In this case the module was on how to quickly and completely perform a patient assessment of a medical patient. The assessment was introduced as an ungraded in-class activity. Before the administration of each assessment students received an instruction sheet explaining the purpose of the study, the use of the data, and the contact information of the principal investigator and the research coordinator to direct any questions or concerns about the research process.

Prior to the pre-listening assessment, students were provided with eight hours of lecture instruction on how to perform a patient assessment. They were also given eight hours (two class sessions) of supervision in a practical skills lab to practice patient assessment on simulated patients. They were then given online assignments on patient assessment to complete. After students learned about the topic they were instructed they would be shown a video depicting a patient assessment performed incorrectly. The administration of the assessment did not last more than 5 minutes. The students were asked to identify the mistakes shown in the video. This was accomplished by having students evaluate the incorrect patient assessment by filling out a 14- 
Armstrong and Ferrari-Bridgers. Critical listening skills in EMT students.

https://doi.org/10.32378/ijp.v4i2.192

item questionnaire with three sub-questions for each item asking if the steps were addressed, addressed completely, and in the appropriate sequence (See appendix A). After the pre-listening assessment the course continued on as normal with no additional course lecture time dedicated to patient assessment. However, students were still given assignments and quizzes on the module and practiced the skill of performing patient assessment on simulated patients under the supervision of an instructor in their practical skills lab. Four weeks later the post listening assessment was administered following the same procedures as the original listening assessment. The pre and post assessments were examined to look for improvement in critical listening ability. The investigators also looked at academic markers for signs of improved academic or practical performance in the course.

\section{Results}

In this study 51 EMT students aged 18-41 participated and were assessed over three separate courses. Overall the results of the study showed a positive increase in the participants' listening skills between the pre and the post assessments, and a positive increase in academic performance. The data analysis of the participants' performance in the pre and post-assessments yielded positive results for both item and sample analysis. The item analysis total mean and SD for the pre and the post-assessments of the questions were $M_{P R E}=28.30, S D_{P R E}=8$. and $M_{P O S T}=$ 38.07, SDPOST $=8.3$. The overall change of participants' performance on the 42 items over time was calculated using the percent change, which measures the extent to which variable gains or loses intensity, magnitude, extent, or value over time. An overall percent increase of $34.50 \%$ was found between the pre and the post assessment results. 
Armstrong and Ferrari-Bridgers. Critical listening skills in EMT students.

https://doi.org/10.32378/ijp.v4i2.192

Since the authors were interested in whether participants improved between pre and post-test, a paired t-test was performed to compare the item means. The t-test was significant, $t(41)=-$

$11.75, p<.00$. The results indicated that participants significantly improved on answering all the questions from the pre to the post-assessment. The effect size was large (Cohen's $d=1.2$ ) and practical significance was with associated test power at $1-\beta=.95$.

Paired-samples t-tests using pre and post data for each of the 42 questions were also conducted.

Only a small number of these per-item differences were significantly different. These comparisons are summarized on Table 1.

Table 1

Pre and Post Mean, SD, and Percent Change for EMT Listening Assessment

\begin{tabular}{|c|c|c|c|c|c|c|}
\hline \multicolumn{3}{|c|}{$\underline{\text { Pre-Assessment }}$} & \multicolumn{4}{|c|}{ Post-Assessment } \\
\hline Question & Mean & $S D$ & Mean & $S D$ & $\%$ Change & $t \& p$ levels \\
\hline $1 \mathrm{~A}$ & 0.49 & 0.50 & 0.75 & 0.44 & 0.5 & Non-significant \\
\hline $1 \mathrm{~B}$ & 0.47 & 0.50 & 0.65 & 0.48 & 0.4 & $\mathrm{t}(1)-2.76 ; \mathrm{p}<.071$ \\
\hline $1 \mathrm{C}$ & 0.35 & 0.48 & 0.55 & 0.50 & 0.6 & Non-significant \\
\hline $2 \mathrm{~A}$ & 0.94 & 0.24 & 0.94 & 0.24 & 0.0 & $\mathrm{t}(1) 0.0 ; \mathrm{p}<1.000$ \\
\hline $2 \mathrm{~B}$ & 0.76 & 0.43 & 0.94 & 0.24 & 0.2 & Non-significant \\
\hline $2 \mathrm{C}$ & 0.76 & 0.43 & 0.92 & 0.27 & 0.2 & Non-significant \\
\hline $3 \mathrm{~A}$ & 0.57 & 0.50 & 0.67 & 0.48 & 0.2 & $\mathrm{t}(1)-1.00 ; \mathrm{p}<.322$ \\
\hline $3 \mathrm{~B}$ & 0.53 & 0.50 & 0.78 & 0.42 & 0.5 & Non-significant \\
\hline $3 \mathrm{C}$ & 0.37 & 0.49 & 0.51 & 0.50 & 0.4 & $\mathrm{t}(1)-1.27 ; \mathrm{p}<.212$ \\
\hline $4 \mathrm{~A}$ & 0.39 & 0.49 & 0.31 & 0.47 & -0.2 & $\mathrm{t}(1) 0.89 ; \mathrm{p}<.376$ \\
\hline $4 B$ & 0.43 & 0.50 & 0.53 & 0.50 & 0.2 & $\mathrm{t}(1)-1.15 ; \mathrm{p}<.255$ \\
\hline $4 C$ & 0.53 & 0.50 & 0.82 & 0.39 & 0.6 & Non-significant \\
\hline $5 \mathrm{~A}$ & 0.71 & 0.46 & 0.84 & 0.37 & 0.2 & $\mathrm{t}(1)-1.85 ; \mathrm{p}<.070$ \\
\hline $5 B$ & 0.33 & 0.48 & 0.71 & 0.46 & 1.1 & Non-significant \\
\hline $5 \mathrm{C}$ & 0.45 & 0.50 & 0.82 & 0.39 & 0.8 & Non-significant \\
\hline $6 \mathrm{~A}$ & 0.86 & 0.35 & 0.90 & 0.30 & 0.0 & $\mathrm{t}(1) 0.63 ; \mathrm{p}<.532$ \\
\hline $6 \mathrm{~B}$ & 0.55 & 0.50 & 0.82 & 0.39 & 0.5 & Non-significant \\
\hline $6 \mathrm{C}$ & 0.39 & 0.49 & 0.37 & 0.49 & -0.1 & $\mathrm{t}(1) 0.22 ; \mathrm{p}<.830$ \\
\hline $7 \mathrm{~A}$ & 0.67 & 0.48 & 0.92 & 0.27 & 0.4 & Non-significant \\
\hline
\end{tabular}


Armstrong and Ferrari-Bridgers. Critical listening skills in EMT students.

https://doi.org/10.32378/ijp.v4i2.192

$\begin{array}{lllllll}\text { 7B } & 0.47 & 0.50 & 0.69 & 0.47 & 0.5 & \text { Non-significant } \\ \text { 7C } & 0.53 & 0.50 & 0.84 & 0.37 & 0.6 & \text { Non-significant } \\ \text { 8A } & 0.57 & 0.50 & 0.90 & 0.30 & 0.6 & \text { Non-significant } \\ \text { 8B } & 0.27 & 0.45 & 0.53 & 0.50 & 0.9 & \text { Non-significant } \\ \text { 8C } & 0.63 & 0.49 & 0.90 & 0.30 & 0.4 & \text { Non-significant } \\ \text { 9A } & 0.63 & 0.49 & 0.80 & 0.40 & 0.3 & \mathrm{t}(1)-2.02 ; \mathrm{p}<.048 \\ \text { 9B } & 0.41 & 0.50 & 0.55 & 0.50 & 0.3 & \mathrm{t}(1)-1.48 ; \mathrm{p}<.146 \\ \text { 9C } & 0.53 & 0.50 & 0.82 & 0.39 & 0.6 & \text { Non-significant } \\ \text { 10A } & 0.82 & 0.39 & 0.94 & 0.24 & 0.1 & \text { Non-significant } \\ \text { 10B } & 0.49 & 0.50 & 0.75 & 0.44 & 0.5 & \text { Non-significant } \\ \text { 10C } & 0.39 & 0.49 & 0.53 & 0.50 & 0.4 & \mathrm{t}(1)-1.41 ; \mathrm{p}<.164 \\ \text { 11A } & 0.82 & 0.39 & 0.94 & 0.24 & 0.1 & \mathrm{t}(1)-1.95 ; \mathrm{p}<.057 \\ \text { 11B } & 0.45 & 0.50 & 0.65 & 0.48 & 0.4 & \mathrm{t}(1)-1.87 ; \mathrm{p}<.067 \\ \text { 11C } & 0.57 & 0.50 & 0.80 & 0.40 & 0.4 & \text { Non-significant } \\ \text { 12A } & 0.73 & 0.45 & 0.94 & 0.24 & 0.3 & \text { Non-significant } \\ \text { 12B } & 0.57 & 0.50 & 0.75 & 0.44 & 0.3 & \mathrm{t}(1)-1.84 ; \mathrm{p}<.071 \\ \text { 12C } & 0.59 & 0.50 & 0.86 & 0.35 & 0.5 & \text { Non-significant } \\ \text { 13A } & 0.43 & 0.50 & 0.65 & 0.48 & 0.5 & \text { Non-significant } \\ \text { 13B } & 0.57 & 0.50 & 0.75 & 0.44 & 0.3 & \mathrm{t}(1)-2.02 ; \mathrm{p}<.048 \\ \text { 13C } & 0.56 & 0.50 & 0.76 & 0.43 & 0.4 & \mathrm{t}(1)-2.02 ; \mathrm{p}<.049 \\ \text { 14A } & 0.76 & 0.43 & 0.94 & 0.24 & 0.2 & \text { Non-significant } \\ \text { 14B } & 0.63 & 0.49 & 0.61 & 0.49 & 0.0 & \mathrm{t}(1) 0.21 ; \mathrm{p}<.837 \\ \text { 14C } & 0.33 & 0.48 & 0.69 & 0.47 & 1.1 & \text { Non-significant }\end{array}$

Cronbach's alpha statistics were calculated to measure the internal-consistency reliability of the assessment tool. The test yielded a Cronbach's alpha coefficient for the 42 items of the EMT assessment. The pre and post-test results were respectively at $\alpha=.86$ and $\alpha=.72$ which indicated strong test reliability for an exploratory study (36).

For the sample analysis the total mean and SD for the pre and the post-assessments of the participants' performance were $M_{P R E}=80.60, S D P R E=5.7$. and $M_{P O S T}=86.90, S D P O S T=10.3$. Similarly, a paired t-test on the sample was performed to investigate the difference between the participants' performance in the pre and post-test. This second t-test was also significant, $t(50)=$ 
Armstrong and Ferrari-Bridgers. Critical listening skills in EMT students. https://doi.org/10.32378/ijp.v4i2.192

$-5.6, p<.00$ which showed that individual participants answered questions more correctly in the post-assessment than in the pre-assessment. The effect size was large (Cohen's $d=.7$ ) and showed practical significance with an associated test power of $1-\beta=.95$. To sum up, the high value of Cronbach alpha and the significant results of the sample and items t-tests both confirmed that participants can effectively improve their skills in a short period of time using listening activities in the classroom.

Finally, we looked at the effects of prior knowledge and/or familiarity with the content on the pre and post listening assessments. We used participants' grade as a measure of participants' familiarity with the content and the pre and post listening assessment scores as a measure of critical listening skills. We performed a regression analysis between the pre and post listening scores (dependent variable) and the grades participants obtained in Exam 3 and in Patient Assessment module (independent variables).We assumed that if participants' familiarity with the content was an important factor in determining listening improvement, familiarity would make up for a large portion of the variance of the pre and post sample data. In particular one should expect a much larger variance for familiarity in the post assessment given that familiarity is expected to increase between the pre and the post assessments. During the pre-assessment, the Beta value for the two independent variables was $\beta_{\text {EXAM } 3}=.095 \beta_{\text {PATIENTASSESSMENT }}=.069$ with no significant $t$ and $F$ values and with familiarity explaining only a minimal portion of the variance in listening scores, $R^{2}=.011$. Similarly, no significant results were found for the post assessment with $\beta_{\text {EXAM3 } 3}=-.095$, and $\beta_{\text {PATIENTASSESSMENT }}=.196$ both with no significant $t$ and $F$ values and a combined $R^{2}=.065$. As the data analysis showed, familiarity with the content occupies only $1 \%$ and $6.5 \%$ of the respective pre and post listening data variances. In other 
Armstrong and Ferrari-Bridgers. Critical listening skills in EMT students.

https://doi.org/10.32378/ijp.v4i2.192

words, familiarity with the content does not seem to have an effect on listening scores. More interestingly, there is no significant increase of variance for familiarity from the pre to the post, which shows that an increase in familiarity is not necessarily reflected in participants listening scores. These results seem to confirm the findings of the aforementioned studies on listening and second language learners suggesting that prior knowledge or familiarity with a topic does not determine how well a student can critically listen to a message. Nevertheless, more data is necessary to confirm these initial findings.

As far as the claim that assessing course content through a listening test such as the FLVLT has a positive impact on participants learning, the comparison between the participants' grades in the Patient Assessment (PA) module 3, and in other modules, such as module 2 oxygen delivery and airway management, shows participants perform better in the module that has been emphasized with listening exercises and assessment. For instance, participants' grades in module 3 were statistically significantly higher than grades in module 2 exam (see table $2,1 \mathrm{a}-1 \mathrm{~b}$ ) Table 2

\begin{tabular}{|c|c|c|c|}
\hline Assessment type & $\begin{array}{l}\text { Mean } \\
(\mathrm{SD})\end{array}$ & Comparison & t-test \\
\hline 1a. Module 2 & $81.3(5.7)$ & Module 2vs Module 3 & $\mathrm{t}(50): 4.4 \mathrm{p}<.05$ \\
\hline 1b. Module 3 & $85.3(6.7)$ & & \\
\hline 2a. Certifying Exam & $80.1(5.7)$ & Certifying Exam vs Exam_PA & $\mathrm{t}(50): 5.59 \mathrm{p}<.05$ \\
\hline 2b. Certifying Exam_PA & $\begin{array}{l}86.9 \\
(10.3)\end{array}$ & & \\
\hline
\end{tabular}


Armstrong and Ferrari-Bridgers. Critical listening skills in EMT students. https://doi.org/10.32378/ijp.v4i2.192

\begin{tabular}{|l|l|l|l|}
\hline 2c. Certifying_Intro & 79.9 & PA vs Intro & $\mathrm{t}(50): 3.4 \mathrm{p}<.05 . ;$ \\
\hline 2d. Certifying Exam_Shock & $76.7(8.1)$ & PA vs Shock & $\mathrm{t}(50): 6.28 \mathrm{p}<.05$ \\
\hline 2e.Certifying exam_Medicine & $80.1(9.8)$ & PA vs Medicine & $\mathrm{t}(50): 4.27 \mathrm{p}<.05$ \\
\hline 3a. Skill Exam_Midterm & 72.5 & Midterm vs Final & $\mathrm{t}(50):-6.2 \mathrm{p}<.05$. \\
& $(19.5)$ & & \\
\hline 3b. Skill Exam_Final & 93.5 & & \\
& $(12.9)$ & & \\
\hline
\end{tabular}

Similarly, at the end of the term participants took the EMT certifying exam. Participants scored significantly higher in the section of the certifying exam that was dedicated to the Patient Assessment module than in the overall exam (Table 2, 2a-2b). In the same manner, participants scored significantly higher in the section of the certifying exam dedicated to the patient assessment than to the other portions of the exam such as the introduction (2c), shock (2d) and medicine (2e), (see Table 2 2b-2e )

Finally, participants took two practical skills exams where they had to demonstrate how to perform a patient assessment in front of their instructors. The midterm skills exam was taken right after the listening pre-assessment test and the final skill exam was taken right after the listening post assessment. The data indicated participants performed much better in the final skill exam with a percentage change difference of $28.9 \%$ (see Table $1,3 a-3 b$ ). 
Armstrong and Ferrari-Bridgers. Critical listening skills in EMT students.

https://doi.org/10.32378/ijp.v4i2.192

To confirm the validity of the results we drew a comparison between participants' grades of the present cohort with students' grades from the past cohorts whose listening skills were not assessed. We selected the scores of 51 random students from past cohorts. The data showed that participants in the present cohort performed better in their part of the EMT state exam dedicated to Patient Assessment (see table 3,1a-1b) and the EMT Certifying exam. (see table 3, 2a-2b). Also, the data indicated that the percentage change difference between the midterm and final skill exams of this present cohort is much higher than the percentage change difference of the old cohorts (see table 3, 3a-3b). As far as the Exam 3, the results are borderline significant given the p-value $<.07$ (see table 3, 4a-4b).

Table 3

\begin{tabular}{|l|l|l|}
\hline Assessment type & Mean (SD) & t-test \\
\hline 1a. Certifying Exam_PA_old & $76.2(10.6)$ & $\mathrm{t}(50):-6.37 \mathrm{p}<.05$. \\
1b. Certifying Exam_PA_new & $86.9(10.2)$ & $\mathrm{t}(50):-1.79 \mathrm{p}<.05$. \\
\hline 2a. Certifying Exam_old & $78.2(7.5)$ & \\
2b. Certifying Exam_new & $80.6(5.6)$ & Percentage Change \\
\hline 3a. Skill Exam_Midterm_old & $80.9(16.8)$ & $13.9 \%$ \\
\hline 3b. Skill Exam_Final_old & $92.3(6.2)$ & $\mathrm{t}(50):-1.45 \mathrm{~ns}, \mathrm{p}<.07$ \\
\hline 4a. Module 3_old & $83.5(5.8)$ & \\
\hline 4b. Module_3_new & $85.3(5.6)$ & \\
\hline
\end{tabular}

The comparison with past student cohorts partially confirms the positive impact listening have on participants' performance, however, more data needs to be collected to replicate the study to 
Armstrong and Ferrari-Bridgers. Critical listening skills in EMT students.

https://doi.org/10.32378/ijp.v4i2.192

confirm the validity of the present results. The results of this study clearly suggest participants seem to perform better in the module assessed through listening than in the other modules studied in the same semester. Therefore, emphasizing critical listening exercises seems to positively impact participants' grades.

\section{Discussion}

Effective listening is a highly valued skill both in and out of the classroom. In an EMT course listening is the most common mode instructor's use to present information for students to receive. It is also often the only way students are presented information during practical skill exams and during scenario-based learning. Out of the classroom and in the field, listening is the primary way EMTs will receive information. However as stated previously the effectiveness of listening in the emergency setting can be challenged by several factors, such as contact time, patients with challenging behaviors, patients with problematic conditions, multi-tasking, communicating with other first responders, and a lack of formal education on communication skills $(24,37)$. Given the importance of critical listening skills in emergency medicine we tested the assumption that by just adding listening exercises and assessments to the coursework, students have the ability to improve critical listening skills and that such improvement is reflected in the students' performance.

The data clearly showed participants significantly improved their critical listening skills in the course of four weeks. This is valuable in itself because it shows that dedicating time specifically to listening exercises can improve listening ability. The benefits of improving this critical skill are obvious. The results further indicate, participants significantly improved answering all the 
Armstrong and Ferrari-Bridgers. Critical listening skills in EMT students.

https://doi.org/10.32378/ijp.v4i2.192

questions from the pre to the post-assessment. Participants improved the most in being able to determine if critical steps were being assessed and being assessed completely but participants also improved their ability to listen for sequencing errors. The biggest improvements in listening to determine if the requisite steps were being accomplished was during the primary assessment. This is a favorable finding because it is supposed to be a quick check to determine life threats. The area with the biggest improvements regarding listening for completeness and sequencing was during the secondary assessment. This is a favorable finding because this is where the EMT is supposed to gather as much information as possible on the patient's condition. Participants did not make as much improvement during the scene size up stage but that may be because students may see this stage more as rote memory and performed quickly as a precursor to the assessment.

As far as the analysis of the 42 individual questions, there was variation in the level of improvement on each question from pre- to post-testing. Part of the variation may be due to the detail and density of the steps. For example, questions 3B, 7A, 7B, 8A, 8B, 10A, 10B, 12A, and 13A contain multiple components and participants have to listen for multiple details to answer an individual question correctly which makes it more challenging. Another difficulty is the steps to some questions like $1 \mathrm{~A}$ are addressed very quickly and could easily be missed. Sequencing questions like 1C, 2C, 4C, 5C, 7C, 8C, 9C, 11C, 12C, and 14C are challenging because the correct sequence is determined on the patient presentation which is unfolding as they watch the video so participants will often have to think back after the assessment has completed to answer these questions correctly. 
Armstrong and Ferrari-Bridgers. Critical listening skills in EMT students.

https://doi.org/10.32378/ijp.v4i2.192

The data showed improvement in performance in the module of patient assessment where the listening exercises were emphasized. Participants performed statistically better on the patient assessment section of the written certifying exam than the exam as a whole and compared to the other sections. This is noteworthy because this was the only section in which the listening exercises were administered during the course. It is plausible to assume there would be similar improvements in the other sections if listening was emphasized there as well. The improvement in the patient assessment section is particularly notable because this information is more likely to be asked at higher level. Patient assessment questions often rise to the level of comprehension, application, and analysis. The listening exercises were presumably effective because they were presented in the specific way students will be expected to gain that information from an actual patient.

To get a better idea of how the participants would perform upon entry into the field we also looked for improvement in their performance during practical skills exams where they were actually relying on their listening ability to garner information from their instructors and patients. The data indicated participants performed much better in the final skill exam with a $28.9 \%$ improvement in performance. The improvement in the final practical summative exam results may be the most significant result of the study as it is the last check on the student's practical performance. Their performance at this stage will translate directly to the field as they start to see real patients.

Such an improvement should be interpreted as a positive sign indicating that having students participate in listening exercises and assessments can have a great impact in their listening ability 
Armstrong and Ferrari-Bridgers. Critical listening skills in EMT students.

https://doi.org/10.32378/ijp.v4i2.192

and their classroom performance. Therefore, despite the fact that the assessment instrument described in this article was used for the first time to examine critical listening ability in EMT students, the results are promising and suggest that this instrument can be a valuable tool to measure critical listening competency and to help future EMTs properly develop critical listening skills.

\section{Limitations}

This study is exploratory in nature and although the results are positive, more data needs to be collected to verify the validity of our results. In the next phase of our research we plan to increase our sample size and to collect, compare and contrast listening scores and grades from students from an experimental and a control group. The presence of a control group will enable us to better understand the effects of teaching critical listening skills on students' performance. The study also shows critical listening exercises can improve performance while in training, but this study does not show whether these exercises make them perform better as EMTs in the field. This will require further examination.

\section{Conclusion}

The results suggest performing critical listening exercises and assessments can help EMT students properly develop this very important skill. 


\section{References}

1. Jackson SW. The listening healer in the history of psychological healing. American Journal of Psychiatry. 1992;149:1623-32. https://doi.org/10.1176/ajp.149.12.1623

2. Fassaert T, van Dulmen S, Schellevis F, Bensing J. Active listening in medical consultations: Development of the active listening observation scale (ALOS-global). Patient education and counseling. 2007;68:258-264. https://doi.org/10.1016/j.pec.2007.06.011

3. Simpson M, Buckman R, Stewart M, Maguire P, Lipkin M, Novack D, et al. Doctor-patient communication: the Toronto consensus statement. BMJ 1991;303:1385-7. https://doi.org/10.1136/bmj.303.6814.1385

4. Robertson K. Active listening. More than just paying attention. Aust Fam Physician 2005;34:1053-5. https://www.racgp.org.au/afp/200512/5780

5. Davis J, Thompson CR, Foley A, Bond CD, DeWitt J. An examination of listening concepts in the healthcare context: differences among nurses, physicians, and administrators. International Journal of Listening. 2008;22:152-167. https://doi.org/10.1080/10904010802181524

6. Mckenna L, Brown T, Boyle M, Williams B, Palermo C, Molloy E. Listening and communication styles in nursing students. Journal of Nursing Education and Practice. 2014;4(11). https://doi.org/10.5430/jnep.v4n11p50

7. Lieberman JA, Stuart MR, Robinson SA. Communication Skills: Enhance the Patient Visit With Counseling and Listening Skills. Family Practice Management. 1996;3:69-78.

8. Meyer GS, Amheim L. The power of two: improving patient safety through better physicianpatient communication. Family Practice Management. 2002; 9(1):47-8. https://www.aafp.org/fpm/2002/0700/p47.html

9. Kvrgic Z, Asiedu GB, Crowson CS, Ridgeway JL, Davis JM. "Like No One Is Listening to Me": A Qualitative Study of Patient-Provider Discordance Between Global Assessments of Disease Activity in Rheumatoid Arthritis. Arthritis Care \& Research 2018;70:1439-47. doi:10.1002/acr.23501. 
Armstrong and Ferrari-Bridgers. Critical listening skills in EMT students.

https://doi.org/10.32378/ijp.v4i2.192

10.Kuehl SP. Communication Tools for the Modern Doctor Bag. Physician Patient Communication Part 1: Beginning of a medical interview. Journal of Community Hospital Internal Medicine Perspectives 2011;1:8428. doi:10.3402/jchimp.v1i3.8428.

11. Hickson GB, Clayton PB, Giethen PE, Sloan FA. Factors that prompted families to file medical malpractice claims following perinatal injuries. Journal of American Medical Association. 1992; 267:2359-1363. https://doi.org/10.1001/jama.1992.03480100065032

12. Klostermann BK, Slap GB, Nebrig DM, Tivorsak TL, Britto MT. Earning trust and losing it: adolescents' views on trusting physicians. Journal of Family Practice. 2005;54(8):679-687. https://www.mdedge.com/familymedicine/article/60374/earning-trust-and-losing-it-adolescentsviews-trusting-physicians

13. Roter DL, Stewart M, Putnam SM, Lipkin M, Stiles W, Inui TS. Communication patterns of primary care physicians. Journal of the American Medical Association. 1997;277:350-357. https://doi.org/10.1001/jama.277.4.350

14. Trahan BC, Rockwell, P. The effects of listening training on nursing home assistants. International Journal of Listening. 1999; 13: 62-1 A. https://doi.org/10.1080/10904018.1999.10499027

15. Brown RF, Butow PN, Henman M, Dunn SM, Boyle F, Tattersall M. Responding to the active and passive patient: Flexibility is the key. Health Expectations. 2002;5:236-245. https://doi.org/10.1046/j.1369-6513.2002.00183.x

16. Wanzer MB, Booth-Butterfield M, Gruber MK. Perceptions of health care providers' communication: relationships between patient-centered communication and satisfaction. Health Communication. 2004; 16(3): 363-384. https://doi.org/10.1207/s15327027hc1603_6

17. Jagosh J, Donald Boudreau J, Steinert Y, Macdonald ME, Ingram L. The importance of physician listening from the patients' perspective: enhancing diagnosis, healing, and the doctorpatient relationship. Patient Educ Couns 2011; 85(3): 369-374.

https://doi.org/10.1016/j.pec.2011.01.028

18. Eide H, Frankel R, Bull Haaversen AC, Vaupel KA, Graugaard PK, Finset A. Listening for feelings: identifying and coding empathic and potential empathic opportunites in medical dialogues. Patient Education and Counseling. 2004;54:291-297.

https://doi.org/10.1016/j.pec.2003.09.006

19. Arnold, C. L., Coran, J. J., \& Koropeckyj-Cox, T. (2016). Listening Skills and the Medical Encounter: Perceptions From Practicing Physicians. Florida Communication Journal, 44(2), 110 .

20. Lang F, Floyd MR, Beine KL. Clues to patients' explanations and concerns about their illnesses. A call for active listening. Arch Fam Med. 2000;9:222-7.

https://doi.org/10.1001/archfami.9.3.222 
Armstrong and Ferrari-Bridgers. Critical listening skills in EMT students.

https://doi.org/10.32378/ijp.v4i2.192

21. Macqueen S, Woodward-Kron R, Flynn E, Reid K, Elliott K, Slade D. A resource for teaching emergency medical communication. Clinical Teaching. 2016;13(3):192-6. https://doi.org/10.1111/tct.12423

22. Coiera EW, Jayasuriya RA, Hardy J, Bannan A, Thorpe ME. Communication loads on clinical staff in the emergency department. Med J Aust. 2002;176(9):415-8.

https://doi.org/10.1016/j.annemergmed.2004.04.006

23. Owen C, Hemmings L, Brown T. Lost in translation: Maximizing handover effectiveness between paramedics and receiving staff in the emergency department. Emergency Medicine Australasia. 2009;21(2):102-7. https://doi.org/10.1111/j.1742-6723.2009.01168.x

24. Ferrari-Bridgers F, Vogel R, Lynch B. Fostering and Assessing Critical Listening Skills in the Speech Course. International Journal of Listening. 2015;31(1):19-32.

https://doi.org/10.1080/10904018.2015.1020231

25. Ferrari-Bridgers F, Stroumbakis K, Drini M, Lynch B, Vogel R. Assessing CriticalAnalytical Listening Skills in Math and Engineering Students: An Exploratory Inquiry of How Analytical Listening Skills Can Positively Impact Learning. International Journal of Listening. 2016;31(3):121-41. https://doi.org/10.1080/10904018.2016.1222910

26. Feyten CM. The Power of Listening Ability: An Overlooked Dimension in Language Acquisition. The Modern Language Journal. 1991;75(2):173-80.

https://doi.org/10.1111/modl.1991.75.issue-2

27. Floyd JJ, Clements SM. The Vital Importance of Critical Listening: An Extended Example. International Journal of Listening. 2005;19(1):39-47.

https://doi.org/10.1080/01463378209369465

28. Wolvin, A. D., \& Coakley, C. G. (1988). Listening. Dubuque, IA: William C. Brown.

29. Wolvin, A. D., \& Coakley, C. G. (1992). Listening (4th ed.). Dubuque, IA: William C. Brown.

30. Wolvin, A. D., \& Coakley, C. G. (1996). Listening (5th ed.). New York, NY: McGraw-Hill.

31. Imhoff M, Janusik LA. Development and validation of the Imhof-Janusik Listening Concepts Inventory to measure listening conceptualization differences between cultures. Journal of Intercultural Communication Research. 2006;35:79-98

https://doi.org/10.1080/17475750600909246

32. Chiang, C. S. \& Dunkel, P. (1992). The effect of speech modification, prior knowledge, and listening proficiency on EFL lecture learning. TESOL Quarterly, 26, 345-374.

https://doi.org/10.2307/3587009 
33. Chung, H. (1999). Interrelationships among prior knowledge, prior beliefs, and language proficiency in second language listening comprehension. Unpublished doctoral dissertation, University of Texas, Austin.

34. Jensen, C., \& Hansen, C. (1995). The effect of prior knowledge on EAP listening-test performance. Language Testing, 12, 99-119. https://doi.org/10.1177/026553229501200106

35. Madden, J. P. (2004). The effect of prior knowledge on listening comprehension in ESL class discussions. Unpublished doctoral dissertation, University of Texas, Austin. http://hdl.handle.net/2152/1365

36. Nunnally, J.C. (1978) Psychometric theory. 2nd Edition, McGraw-Hill, New York.

37. Bost N, Crilly J, Patterson E, Chaboyer W. Clinical handover of patients arriving by ambulance to a hospital emergency department: A qualitative study. International Emergency Nursing. 2012;20(3):133-41. https://doi.org/10.1016/j.ienj.2011.10.002 